COMPLETION OF THE CASE

OF

\title{
CONGENITAL HYDRONEPHROSIS
}

\author{
REPORTED IN THE FORTY-EIGHTH VOLUME OF THE \\ 'TRANSACTIONS' OF THE SOCIETY.
}

BY THE IATE

THOMAS HILLIER, M.D., F.R.C.P. LoND., PHYSICIAN TO THE HOSPITAL FOR SICK CHILDREN AND TO THE SKIN DEPARTMENT IN UNIVERSITY COLLEGE HOSPITAL.

Received Oct. 7th, 1868.-Read June 22nd, 1869.

THE history of the case was brought up to December, 1865 , in the paper referred to.

From that time until July, 1868, he was occasionally seen by me, and $I$ had reports of his condition from his father. Once in that period he was tapped and a quantity of urinelike fluid was drawn off. He continued in a weak state of health, very thin, small of his age, and with great distension of the abdomen, which prevented his moving about. His urine was usually clear, free from albumen, and in moderate quantity.

On the 16th July he was again admitted into the Hospital for Sick Children, in consequence of his complaining a good deal of headache and feverishness. He was able at 
this time to sit up and talk with moderate vivacity. There was no marked dyspnœa.

On the 20th he vomited and became drowsy and listless; his face became flushed, and he refused all solid food. His temperature in the axilla was $103^{\circ} \mathrm{Fahr}$.

23rd.-Still almost unconscious. Pulse 144, weak; respiration 56 , temperature $101 \cdot 2^{\circ}$. Some moist sounds over the base of right lung. Passes urine involuntarily.

25th.-Some return of consciousness. Occasional twitching of hands. Dulness of percussion noted over base of right lung, with moist sounds over both bases. Pulse 84 , very irregular. Temperature $101^{\circ}$. Sordes of mouth and teeth. Takes food a little better.

27th.-Still drowsy, but looks better. Pulse 144, respiration 70. He spoke this morning. Alæ nasi dilate with inspiration.

28th.-Pupils large, very sluggish, left more dilated than right. Bowels confined, motions passed in bed without notice. Pulse 124, not quite regular. Respiration 40.

29th.-Lies on his back, never speaks; sleeps nearly all day. Has not passed water for twenty-four hours.

30th.-Passed plenty of water last night, which was free from albumen, contained uric acid and epithelial scales of squamous variety. Temperature $101^{\circ}$. Too ill for chest to be examined.

August 1st.-Pulse 162 ; respiration 36.

3rd.-Gradually sinking; can scarcely swallow.

On the 5 th he died.

Post-mortem examination, twenty hours after death. Weight twenty-seven pounds. Much emaciated; arms and legs somewhat deformed from rickets.

Abdomen. - Circumference twenty-four inches. On opening the abdominal walls a large cyst was found filling the greater part of the cavity, free from adhesions anteriorly. The small intestine lay over the upper part of the cyst; some of the mesentery was adherent to the upper part, and some to the lower, as if the large mass had come forwards between the mesenteric folds. The duodenum was 
adherent to the upper and left side of the cyst. The peritoneum in the right lumbar region was reflected in a vertical line with the anterior spine of the ilium. The left kidney, seen in situ, did not appear much enlarged. On tearing away the cyst from its attachments in the right loin, its posterior portion was found to occupy the situation of the right kidney, and the supra-renal body, of normal size and appearance, was found attached to it. In the right loin the cyst presented a constriction, behind which a portion of the cyst presented somewhat the appearance of a greatly enlarged kidney; the colour, however, was pale and bladder-like. One very small part of the cyst-wall near what would be the hilus of this reniform part of the cyst showed a very pale kidney colour. The main body of the cyst in front of this was globular or rather ovoid. The ureter was found proceeding from the lower part of the cyst, attached for about an inch to its wall. This ureter, examined from the vesical extremity, was found to enter by a much smaller orifice than usual. A small dressing probe was with difficulty passed up the ureter, being very firmly grasped, especially near the bladder. When the probe had been passed to within two inches of the cyst and withdrawn, fluid could be squeezed out of the cyst through the ureter into the bladder by drops. Previously to the passage of the probe none of the contents of the cyst escaped on pressure. The ureter externally presented nothing abnormal in its appearance, but was smaller than normal.

The left ureter was distended at its upper two thirds to about an inch in diameter. At its lower end it was of natural size and contained calculous matter, which formed an obstruction to the flow of fluid, which could, however, be without difficulty overcome. The pelvis of this kidney was dilated snfficiently to contain a small pigeon's egg, and contained a little calculous matter. On examination the gravel was found to consist of uric acid.

The cyst measured twenty-seven inches in circumference over the long diameter, and twenty-four inches over the short one. It was nine inches long by eight wide, and six 
and a half inches deep. It contained eighty-three ounces of clear fluid, having a pale lemon colour and urinous smell. Sp. gr. 1002, very slightly acid, with the faintest trace of albumen, and presenting under the microscope a few brokendown cells of large size. The mesenteric glands were enlarged and hard. Intestines healthy.

Liver weighed sixteen ounces, healthy, except that on its upper and under surface were a few small tubercles. There were also a few on the peritoneal aspect of the diaphragm.

Spleen weighed one ounce six drachms, and contained tubercles on the surface and a few in its substance.

Heart weighed two and three quarter ounces, healthy.

Lungs contained miliary tubercles scattered throughout their substance. The lower lobe of the right lung was collapsed.

Brain.-On the upper surface of right hemisphere, extending also between the falx and the hemisphere, binding them together, was a little lymph of recent date. The convolutions were flattened and had a fluctuating feel near the anterior part of cerebrum. The anterior lobes were rather softer than normal, but not redder; both lateral ventricles were filled with a large amount of clear fluid. All the central parts of the brain were softened, the right anterior lobes near the corpus striatum were almost creamy. In the centre of the left corpus striatum was a small body about the size of a pea ; the nerve substance around was soft, but not red. It was firm and contained a creamy matter. Under the microscope the creamy matter looked like degenerated nervecells; there were no pus-globules visible. At the base of the brain there was lymph near the olfactory nerves, around the optic commissures and to a less degree around the pons and the nerves arising from this part. There were granules of tubercle in Sylvius's fissures.

Remarks.-The post-mortem examination quite confirmed the diagnosis which was made during life. As was supposed, the great distension of the abdomen was due to an obstruction in the right ureter, causing an enormous accumulation of urine in the pelvis of the kidney. The exact 
nature of the obstruction could not be ascertained during life. It was either congenital or occurred almost immediately after birth. It was not of such a character as at all times to prevent the passage of fluid from the kidney to the bladder, because there was distinct evidence that occasionally the obstruction was overcome for a time, when distension had been very great.

The obstruction was found to be due to an abnormally small ureter, a congenital stricture, through which fluid did not usually pass, although it might do so under extreme pressure from dilatation. The pelvis of the left kidney was also somewhat dilated, as was anticipated, though not to so great an extent. The dilatation on this side was due to a formation of calculous matter, which occasionally clogged up the ureter. The patient died from acute tuberculosis.

With the experience derived from this case I cannot see that any fresh indications for treatment in a similar case are to be obtained.

The extirpation of the right kidney was discussed; but it was considered to be an unjustifiable proceeding, especially in a patient of such a feeble constitution as this boy.

The fatal results which have attended extirpation of the kidney in animals tend to discourage any attempts to adopt this operation in the human subject.

Tapping was attended with temporary relief, but fluid rapidly reaccumulated, and after a short time irritative fever was set up, and the fluid became purulent and albuminous. During the later period of his life the operation was not repeated, for although the distension was very great it seemed not to increase beyond a certain point. There was probably a small escape of fluid through the constricted ureter constantly going on. 